sequence is fortuitous. But if that is the case, what other codons, apart from AUG or UGA, are needed for initiation and termination of protein synthesis? The answers to these questions depend on the analysis of more termination and initiation fragments.

Although the determination of R17 initiation and termination signals has left several questions unanswered, the process of initiation of protein synthesis in bacteria is reasonably well understood. Unfortunately the same cannot be said for mammalian and other eukaryotic cells; there is still no clear idea how protein synthesis in these cells is initiated or terminated. At last, however, a promising experimental system for tackling the problem has been developed. On page 184 Smith, Marcker and Mathews, who, like Steitz and Nichols, work at the MRC's Molecular Biology Laboratory at Cambridge, describe a cell-free system from ascites cells which accurately translates RNA from encephalomyocarditis virus. This group is now in a position to explore mammalian protein synthesis in much the same way that bacterial protein synthesis has been investigated with $E$. coli cell-free systems programmed with RNA phage RNA. Whether or not mammalian proteins are initiated with amino-acids with blocked or free amino-groups is the sort of question that Marcker's group should soon be able to answer.

\title{
Harwell's UFOs brought down to Earth
}

THE agreeably Rabclaisian solution to a puzzle which, faute de mieux, served as Nature's Christmas quiz to its readers, appears on page 199 of this issue. The problem was posed by R. D. Wiffen and M. J. Heard of the Atomic Energy Research Establishment at Harwell, who discovered an unusual class of objects, less than half a micron across, in the air round Harwell. From their regular size and structure the objects appeared to be biological in origin, but none of the twelve research institutes to which Wiffen and Heard applicd for advice were able to identify them.

More than a year after the objects had first come to light, and with their identity no nearer solution, the Harwell physicists took their courage in both hands and publicly appealed to the world's biological community for what holp it could give (Nature, 224, 715; 1969). Before learning the answer readers should scrutinize the micrograph below. The "unidentified airborne organisms" resemble both spores and radiolarian skeletons, but Wiffen and Heard had been advised that neither interpretation was corrcct.

Credit for solving the AERE riddle goes to A. C. Neville of Oxford and David S. Smith of Miami, who point out that the objccts are brochosomes, the bizarre cxcretory products of leafhoppers and other homop-

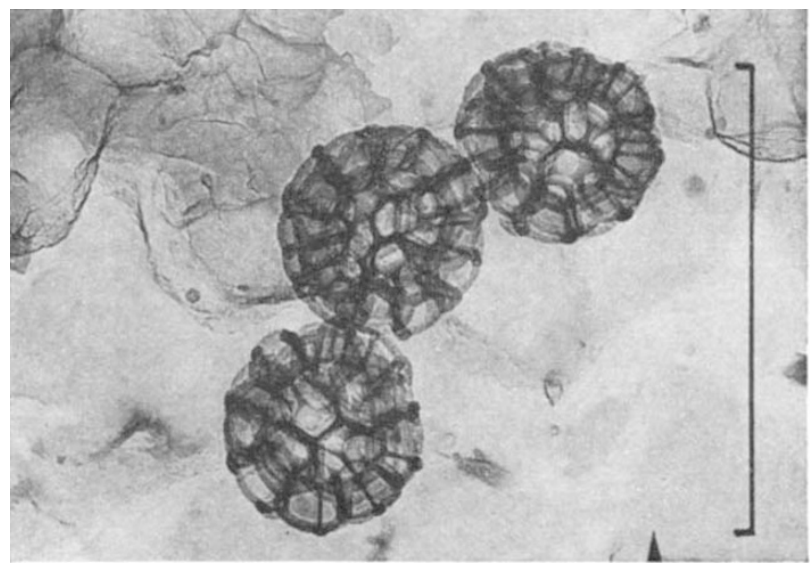

"Unidentified airborne organisms" detected at Harwell (from Nat ure, 224, 715; 1969). Scale: one micron. terous insects. Although brochosomes were first described in 1953 they have not yet made the textbooks, which may be why apparently so few people are familiar with them.

The AERE team have reacted with a mixture of sang-froid and relief to the breaking of their year-long suspense. Dr Heard said on the telephone this week that when they first heard the answer they feared that brochosomes were common knowledge and that Harwell would be drowned in the deluge of replies. But only twelve letters were received in all, of which only four gave the correct solution. Their chief disappointment, Dr Heard said, is that brochosomes do not serve as clues to the origin of the air mass in which they are carried. The air sampling programme at Harwell, part of a study of air pollution, sometimes picks up crystals of sea salt and it was hoped that the unidentified organisms would also prove indicative of the source of the air. Nonetheless their efforts have not been wasted in that brochosomes have not been detected in the air before.

Moreover, the discovery of the brochosomes is an eloquent testimony to Wiffen's and Heard's skill with the electron microscope since, unlike in the light microscope, it is difficult to scan the whole field of view, particularly in search of an object that is unexpected. "It is amazing that they found these things in the first place and a tribute to their diligence of searching," Dr Neville said on the telephone this week. Dr Smith a) so doffs his eap at the efficiency of the Harwell sampling techniques and his amusing remark about the concentration of brochosomes in the Berkshire air will doubtless be seized on by the pesticide manufacturers' lobby.

The incident may also interest connoisseurs of scientific literature, particularly those who like cynically to maintain that 90 per cent of any list of references is aimed at displaying the erudition of the author rather than the antecedents of his paper. Seven of the eight references given by both Neville and Smith are identical (the two papers were written entirely independently), which is a neat exhibition of the principle that underlies their inclusion. 